\title{
Correspondence
}

\section{Navigating the Ship of Theseus from typology to cartography}

\author{
JOHN T. LONGINO \\ Department of Biology, University of Utah, Salt Lake City, Utah, 84112, USA. \\ "="john.longino@utah.edu; |"| https://orcid.org/0000-0001-5465-0293
}

I am a practicing taxonomist who has published revisions and faunistic works on ants. I love the process of collecting ants in the field, preparing them, examining them with a dissecting microscope, comparing them to other specimens in collections, and fitting them into a naming scheme that has been gradually refined over 250 years. In recent years I have increasingly turned to DNA sequence data to augment what I can learn from morphology. DNA sequence data provide a fundamentally new kind of information. Morphology is an emergent property of the interactions of genes, environments, and the processes of development. DNA sequences are the units of inheritance that pass from one individual to the next, recreating morphological patterns in each generation.

Taxonomy is the business of describing and naming organismal diversity. What that means exactly must shift as our conceptual framework shifts (as it did during the time of Darwin) and as what we are able to see shifts as a result of technological assists. We are at a moment of profound conceptual and technological change. Here I give some personal thoughts on three top questions in taxonomy.

\section{Are traditional naming conventions compatible with massive cryptic genetic discontinuity?}

Scientists have persistently underestimated organismal diversity. Early taxonomists developed notions of macrofaunal diversity in Europe and then were faced with the overwhelming diversity of the tropics. As more people joined a scientific class and spent more time collecting and looking at smaller things, they saw ever finer detail and ever more subtle morphological distinctions among species. In the mid twentieth century, taxon proliferation temporarily abated during the era of Mayrian polytypic species, with purported reproductive continuity across geographically variable forms. But such polytypic species had an annoying tendency to co-occur as reproductively isolated entities in parts of their range, and taxonomic splitting recommenced (Hillis 1988). Now, DNA sequencing data reveal the next layer of complexity, hidden within the morphological shells that previous generations called species.

The progressive recognition of diversity is seen in ants, for example. In the 10th edition of the Systema Naturae (1758), Linnaeus recognized 16 species of ants. Subsequent practitioners of nineteenth century ant taxonomy discovered hundreds more. Schemes of trinomials and quadrinomials were devised to accommodate geographically dispersed similar forms. Ever finer parsing of morphological diversity continues to the present, and there are currently over 13,000 valid species (Bolton, 2020).

Geneticdifferentiationmaylongprecedemorphological divergence, and many previously recognized species are mosaics of genetically distinct forms (e.g., Funk et al. 2011). Rapidly evolving genetic elements such as the COI "barcode" region of mitochondria reveal massive population differentiation (e.g., Hebert et al. 2004, Butcher et al. 2012). If most previously described species actually comprise dozens of cryptic species, do we keep racking up the binomials? Are we prepared to increase catalogues by an order of magnitude or more? Will we lose some of the communication function of zoological nomenclature when a morphologically and behaviorally uniform entity goes by a hundred names? Might it be better to have one name go by a hundred sequences?

\section{Can we agree on what we are delimiting and naming?}

Species are delimited and named by taxonomists and are a fundamental unit in analyses (Wilson 2004). Yet attempts to objectively define what species are never succeed. Darwin popularized a view of life in which a single ancestral form gave rise to myriad descendant forms; a root in the distant past, and fine branch tips pushing into the future. The finest divisions, at the branch tips, were species. Darwin operated without a particulate model of inheritance and with no hint of the inner workings of development. Advances in both these areas, especially in the current era of genomics and evolutionary development (evo-devo), reveal just how 
complex the processes are that produce morphological and genetic discontinuities in nature.

Molecular systematics began with the ability to sequence individual nuclear or mitochondrial genes of multiple individuals. The results were used to examine reproductive isolation for biological species concepts and phylogenetic relationships for phylogenetic species concepts. But soon systematists had to acknowledge the discontinuity between genealogies of individual genetic elements and historical population processes shaped by demography, selection, dispersal, and population subdivision. In the early days of molecular systematics, it was disconcerting to see evidence of discordant phylogeny among genes, when the expectation was that genes would consistently reflect the history of lineage divergence. It soon became clear that genes could have histories of diversification that preceded the diversification of the organisms in which they traveled. Stochastic processes distributed the descendant genes into multiple populations (incomplete lineage sorting), such that gene phylogenies neither agreed with each other nor necessarily reflected the history of organismal lineage divergence (e.g., Pollard et al. 2006).

Alternatively, genes can cross species boundaries through hybridization and introgression. The importance of introgression has been revealed by whole genome sequencing, further illuminating the disconnect between gene histories and the evolution of morphological diversity. Major regions of the genome can have disparate genealogical histories. For example, populations of Heliconius butterflies have acquired mimicry genes through adaptive hybrid introgression (Edelman et al. 2019), a phenomenon that may be common and could be the norm in species radiations (Mallet et al. 2016). Mallet et al. apply the philosophical metaphor of the Ship of Theseus to our understanding of species. On this metaphorical ship, timbers and rigging are gradually replaced as they are damaged or worn, until the materials of the ship are completely replaced. The question arises, is it the same ship? It still looks and functions as the same ship. Are species also a Ship of Theseus, with morphology and behavior "floating" on a constantly changing genome?

Species definitions are also affected by discoveries in developmental biology, revealing how even quite complex morphology can evolve in parallel. Deep homology can result in identical phenotypes that have evolved independently, but using the same developmental pathways. Ecological speciation is common (Schluter 2009), with selection favoring morphological divergence across ecotones in the presence of gene flow, and this can occur in parallel in many independent instances. A classic example is sticklebacks, which have repeatedly evolved limnetic and benthic forms in different freshwater lakes.
The developmental genes that differentiate the two forms are ancient, occurring in marine ancestors (Colosimo et al. 2005), but selection favors evolution of the two forms each time they colonize a new lake. Should we use formal species names to refer to each instance of this repeated local speciation?

We have to come to terms with the fact that the individual organisms that we characterize and name are temporary constructs, impermanent collaborations of disparate genetic pieces, like flash mobs that assemble briefly and then dissipate. Life is almost infinitely diverse, but has a "lumpiness" that emerges from a mélange of genealogy, demographics, selection, and development. There is no single species concept, integrative or otherwise, that can be applied uniformly. We can describe the lumps at almost any temporal and spatial scale. Ultimately species are how we choose to name the lumps. O'Hara (1993) likened species delimitation to cartography. Taxonomists make maps of diversity, which may be at any scale. Heretofore the criterion of publication has been sufficient to maintain order in the nomenclatural system, but that is probably no longer the case. Will we be able to establish some form of formal registry and vetting? Will we continue to be the authorities in matters of scientific names, or will we be bypassed by alternative systems that emerge from crowd-sourcing and popular usage?

\section{Can we excite public interest without typology?}

To make sense of the world we rely on typology. We absorb a sensory continuum and construct mental models of reality. Typology comes naturally. More academically oriented taxonomists have eschewed typological species concepts since the nineteenth century, but amateurs delight in a firmly typological approach. The public has a visceral attraction to the discovery of new species, but they are less enthusiastic when you explain that a particular new species is identical to twelve other species. Donoghue and Alverson (2000) rightly explain how we are still in an age of discovery, but it is somewhat disingenuous to not also admit that taxonomists have done a remarkable job of describing life's morphological and behavioral diversity, parsing life into very fine clusters. It is a marvel that I can pick up a $2 \mathrm{~mm}$ long insect from anywhere in the world, and if I am in a major natural history museum I can, in a few steps and perhaps a flight of stairs, pull out a drawer with specimens that look very similar to my find.

Technological assists may allow the public to "see" and thus value genetic diversity in the same way they have been attracted to morphological diversity. It may also allow naturalists to place their discoveries in context without the need to physically go to the museum. The pocket sequencer may augment reality, such that an ant 
at the picnic becomes a series of high-resolution images of what the ant would look like if you were its size. The DNA sequence information retrieves a Latin binomial, which is assigned to a morphological envelope that may contain many genetic clusters. The Latin binomial has a geographic range and a synopsis of behavior and ecology. The DNA information also places your specimen into a genetic landscape. Is your specimen close to other specimens that have been sequenced? How distant is it from its nearest genetic neighbor? Is it different enough be considered a novel genome and thus acquire a special status? If it is in a known genetic cluster, is your specimen within the expected geographic range? How has your observation expanded knowledge and become a permanent contribution to the biodiversity map?

Technological assists have allowed taxonomists not only to see nature in unprecedented detail but to better understand the processes that generate diversity. We need to accommodate these new developments, not only to better describe the natural world to our own satisfaction, but to facilitate and encourage public enthusiasm for the diversity of life.

\section{Funding}

This work was funded by the National Science Foundation, DEB-1932405 (Ants of the World).

\section{References}

Bolton, B. (2020) An online catalog of the ants of the world. Available from http://antcat.org. (accessed 3 January 2020).

Butcher, B.A., Smith, M.A., Sharkey, M.J. \& Quicke, D.L. (2012) A turbo-taxonomic study of Thai Aleiodes (Aleiodes) and Aleiodes (Arcaleiodes) (Hymenoptera: Braconidae: Rogadinae) based largely on COI barcoded specimens, with rapid descriptions of 179 new species. Zootaxa, 3457, 1-232. https://doi.org/10.11646/zootaxa.3457.1.1

Colosimo, P.F., Hosemann, K.E., Balabhadra, S., Villarreal, G., Dickson, M., Grimwood, J., Schmutz, J., Myers, R.M., Schluter, D. \& Kingsley, D.M. (2005) Widespread parallel evolution in sticklebacks by repeated fixation of ectodysplasin alleles. Science, 307, 1928-1933. https://doi.org/10.1126/science.1107239

Donoghue, M.J. \& Alverson, W.S. (2000) A new age of discovery. Annals of the Missouri Botanical Garden, 87, 110-126. https://doi.org/10.2307/2666212

Edelman, N.B., Frandsen, P.B., Miyagi, M., Clavijo, B., Davey, J., Dikow, R.B., García-Accinelli, G., Van Belleghem, S.M., Patterson, N., Neafsey, D.E., Challis, R., Kumar, S., Moreira, G.R.P., Salazar, C., Chouteau, M., Counterman, B.A., Papa, R., Blaxter, M., Reed, R.D., Dasmahapatra, K.K., Kronforst, M., Joron, M., Jiggins, C.D., McMillan, W.O., Di Palma, F., Blumberg, A.J., Wakeley, J., Jaffe, D. \& Mallet, J. (2019) Genomic architecture and introgression shape a butterfly radiation. Science, 366, 594-599.

https://doi.org/10.1126/science.aaw2090

Funk, W.C., Caminer, M. \& Ron, S.R. (2012) High levels of cryptic species diversity uncovered in Amazonian frogs. Proceedings of the Royal Society B: Biological Sciences, 279, 1806-1814. https://doi.org/10.1098/rspb.2011.1653

Hebert, P.D., Penton, E. H., Burns, J.M., Janzen, D.H. \& Hallwachs, W. (2004) Ten species in one: DNA barcoding reveals cryptic species in the neotropical skipper butterfly Astraptes fulgerator. Proceedings of the National Academy of Sciences of the United States of America, 101, 14812-14817. https://doi.org/10.1073/pnas.0406166101

Hillis, D.M. (1988) Systematics of the Rana pipiens complex: puzzle and paradigm. Annual Review of Ecology and Systematics, 19, 39-63. https://doi.org/10.1146/annurev.es.19.110188.000351

Linnaeus, C. (1758) Systema naturae per regna tria naturae, secundum classes, ordines, genera, species, cum characteribus, differentiis, synonymis, locis. Tomus I. Editio decima, reformata. Holmiae [= Stockholm]: L. Salvii, 824 pp.

Mallet, J., Besansky, N. \& Hahn, M.H. (2016) How reticulated are species? Bioessays, 38, 140-149. https://doi.org/10.1002/bies.201500149

O'Hara, R.J. (1993) Systematic generalization, historical fate, and the species problem. Systematic Biology, 42, 231-246. https://doi.org/10.1093/sysbio/42.3.231

Pollard, D.A., Iyer, V.N., Moses, A.M. \& Eisen, M.B. (2006) Widespread discordance of gene trees with species tree in Drosophila: evidence for incomplete lineage sorting. PLOS Genetics, 2, e173. https://doi.org/10.1371/journal.pgen.0020173

Schluter, D. (2009) Evidence for ecological speciation and its alternative. Science, 323, 737-741. https://doi.org/10.1126/science.1160006

Wilson, E.O. (2004) Taxonomy as a fundamental discipline. Philosophical Transactions of the Royal Society of London. Series B: Biological Sciences, 359, 739-739. https://doi.org/10.1098/rstb.2003.1440 